\title{
ASPECTOS GERAIS DA INELEGIBILIDADE POLÍTICA: APÓS CONDENAÇÃO EM SEGUNDA INSTÂNCIA
}

\author{
Veronilde Oliveira De Almeida Junior, Shirley Oliveira Lima Nomura, Fábio Ferreira Morong \\ Universidade do Oeste Paulista - UNOSTE, Curso de Direito, Presidente Prudente, SP. E-mail: \\ veronilde junior@hotmail.com
}

\section{RESUMO}

O presente trabalho dedicou-se a reflexionar, relativamente acerca da inelegibilidade a cargos políticos, após condenação em segunda instância, mesmo sem ter ocorrido o transito em julgada da sentença condenatória, realizando ainda uma ponderação a luz do princípio da presunção da inocência. Foi aplicado, na elaboração o método hipotético-dedutivo, apoiando-se na edificação doutrinária, jurisprudencial e normativa, assim como pesquisa bibliográfica por meio uma ampla leitura de artigos científicos, doutrina e jurisprudência. Conclui-se ao final, que o referido diploma legal, embora seja motivo de constantes discussões na seara jurídica, acerca de sua constitucionalidade constata-se que não há que se falar em inconstitucionalidade, uma vez que nossa Suprema Corte entende que a prisão decretada em segundo grau jurisdicional não fere o princípio da presunção de inocência. Logo, essa regra se aplica também aos agentes políticos, que após terem reafirmado em segundo grau a sentença condenatória proferida pelo juízo a quo, pode ter o início de sua execução decretada, o que de plano acarreta a condição de inelegibilidade política, implicando ao apenado todas as condições negativas que prevê a Lei 135 de 2010.

Palavras-chave: Elegibilidade, Lei da ficha limpa, Condenação em segunda instancia, HC 126.292.

\section{GENERAL ASPECTS OF POLICY INELEGIBILITY: AFTER CONDEMNATION IN SECOND INSTANCE.}

\begin{abstract}
The present work has focused on relative ineligibility for political positions, after a conviction in the second instance, even without having passed the sentence of condemnation, also considering the principle of presumption of innocence. The hypothetical-deductive method was applied in the elaboration, being based on the doctrinal, jurisprudential and normative construction, as well as bibliographical research through a wide reading of scientific articles, doctrine and jurisprudence. It is concluded at the end that the aforementioned law, although it is a reason for constant discussions in the legal arena, about its constitutionality, it is stated that it is not necessary to speak of unconstitutionality, since our Supreme Court understands that the arrest decreed in court does not violate the principle of the presumption of innocence. Therefore, this rule also applies to political agents, who, after having reaffirmed in second degree the conviction handed down by the court, may be commenced, which in full results in the condition of political ineligibility, implying the victim all negative conditions provided for in Law 135 of 2010. Keywords: Eligibility, Clean Sheet Law, Conviction in second instance, HC 126.292.
\end{abstract}

\section{INTRODUÇÃO}

O presente trabalho dedicou-se a reflexionar, relativamente acerca das recentes disposições trazidas com o advento da Lei complementar
135 de 2010, que inclui novas hipóteses de inelegibilidade para cargos políticos, o que ocasionou grandes debates no meio jurídico. 
Tendo em vista que muitos entendem tratar-se de um diploma legislativo inconstitucional por ferir o princípio da presunção de inocência preconizado no artigo 50, inciso LVII, de nossa Magna Carta de 1988.

Assim, para que a trabalho transcorra de forma adequada, foi dividido em quatro capítulos, sendo abordados inicialmente, os conceitos basilares de política, realizando uma abordagem sistêmica do referido fenômeno jurídico social, assim como uma breve evolução histórica do instituto ora estudada.

o segundo capítulo foi dedicado exclusivamente, para uma reflexão acerca da elegibilidade política, assim como, as condições de elegibilidade prevista na Constituição Federal.

O terceiro capítulo, buscou-se refletir acerca da Lei da Ficha Limpa, uma vez que a aprovação da Lei 135 de 2010, trouxe novas causas de inelegibilidade, algo de extrema importância para esta pesquisa.

Posteriormente, foi dedicado um capitulo apenas para analisar sobre o princípio da presunção de inocência, assim como sobre o posicionamento com o julgamento do Habeas Corpus 126.292 julgado pelo Supremo Tribunal Federal.

Para que a pesquisa se concretiza-se adequadamente, será aplicado, na elaboração o método hipotético-dedutivo, apoiando-se na edificação doutrinária, jurisprudencial e normativa, assim como pesquisa bibliográfica por meio uma ampla leitura de artigos científicos, doutrina e jurisprudência.

Concluo ao final, que a prisão, realizada posteriormente a condenação reafirmada pelo tribunais superiores, confirmando a sentença proferida pelo juízo a quo, não atenta contra princípios constitucionais tampouco fere 0 princípio da presunção de inocência, tratando-se de uma prisão plenamente legal, conforme o entendimento de nossa Suprema Corte, no julgamento do Habeas Corpus número 126.292/2016, no qual foi decidido que é possível a execução da pena já a partir de sentença em segunda instância.

\section{METODOLOGIA}

O presente trabalho, em vista seu objetivo, pode ser classificado como exploratório e pautou-se predominantemente em pesquisa bibliográfica e documental.
Para a realização da pesquisa foram utilizados como recursos o levantamento bibliográfico em livros, revistas, jornais, artigos eletrônicos, legislação, jurisprudência e coletados dados em órgãos oficiais. Os resultados foram obtidos por meio do procedimento de análise do conteúdo.

\section{RESULTADOS}

A priori, antes de adentrarmos ao estudo reflexivo acerca da Lei da ficha limpa, insta destacar que atualmente, o referido diploma legal tem se mostrado um instrumento plenamente eficaz, na busca incessante de retirar indivíduos cuja reputação não precede os preceitos éticos para o exercício e gozo das atribuições políticas.

Como visto anteriormente, nossa Magna Carta prevê inúmeros casos de inelegibilidades

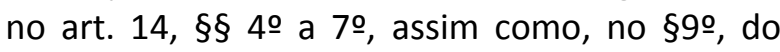
referido artigo, conforme dispõe:

$\S$ 9o Lei complementar estabelecerá outros casos de inelegibilidade e os prazos de sua cessação, a fim de proteger a normalidade $e$ legitimidade das eleições contra a influência do poder econômico (BRASIL, 1988).

Observa-se que o legislador prevendo a necessidade de complementação acerca das disposições sobre inelegibilidade, autorizou a edição de Lei Complementar para dispor sobre outros casos de inelegibilidades relativas, ou seja, que não estão relacionadas com determinada característica pessoal daquele que pretende candidatar-se.

Em consonância com o previsto no referido texto constitucional, foi sancionada, a Lei Complementar no 135 de 2010, que altera a Lei Complementar no 64/1990, trazendo novas hipóteses de inelegibilidade, almejando alcançar proteção máxima dos princípios norteadores da administração pública, no exercício do mandato, com o objetivo de melhorar o perfil dos candidatos aos cargos políticos. (BRASIL, 2010).

Deste modo verifica-se, que a Lei Complementar no 135 de 2010 é uma continuidade da Lei no 9.840/99, que trouxe um novo marco positivo na política brasileira almejando afastar de cargos políticos, indivíduos 
envolvidos em práticas de abusos políticos ou econômicos.

Vale salientar que a Lei da ficha limpa, introduziu ao ordenamento pátrio, novas causas de inelegibilidade, logo se faz necessário ponderar acerca do que vem a ser inelegibilidade.

Segundo Silva (2005), a Inelegibilidade revela-se um impedimento à capacidade eleitoral passiva (direito de ser votado). Obsta, pois, à elegibilidade. Não se confunde com a inalistabilidade, que é impedimento à capacidade eleitoral ativa (direito de ser eleitor), nem com incompatibilidade, impedimento ao exercício do mandato depois de eleito.

Reafirma tal posicionamento ao reflexionar acerca da conceituação aludida por Alexandre de Moraes (2014, p. 233):

A inelegibilidade consiste na ausência de capacidade eleitoral passiva, ou seja, da condição de ser candidato $\quad \mathrm{e}$ consequentemente, poder ser votado, constituindose, portanto, em condição obstativa ao exercício passivo da cidadania.

A inelegibilidade, como se verificou é algo que há muitos anos tem causado relevantes discussões no mundo jurídico, tendo em vista tratar-se de uma temática extremamente importante para um Estado Democrático de Direito.

O fruto de tal condição, e a necessidade de se afastar dos cargos políticos parlamentares cujo comportamento moral não é exemplar, não condizendo assim com o esperado dos representantes, agindo sem ética e decoro.

Entretanto a principal polêmica que gira em torno da constitucionalidade da Lei da Ficha Limpa é a causa de inelegibilidade em face de decisão judicial condenatória que não transitou em julgado.

A Constituição Federal dispõe: Art. 50 (in omissis) "LVII - ninguém será considerado culpado até o trânsito em julgado de sentença penal condenatória". (BRASIL, 1988).

O dispositivo supracitado consagra $O$ princípio da presunção da inocência. Inúmeros juristas entendem que a Lei 135 de 2010 ataca esse princípio logo seria suficiente para considerá-la inconstitucional.

Nesse sentido leciona Silveira (2011, p.11):
A partir de uma análise jurídica, é difícil defender a constitucionalidade da Lei Complementar $n$. 135/10, quando a pretensão é impedir de obter o registro de candidatura a cidadãos que tiverem condenação criminal por órgão colegiado, ainda que caiba recurso, porque definidos como 'inelegíveis', porque afronta a presunção de inocência conforme aponta a Constituição Federal, onde só poderá ser considerado criminoso depois da sentença condenatória transitada em julgado.

Como visto, inúmeros juristas entendam pela inconstitucionalidade da Lei 135 de 2010, conhecida como Lei da Ficha Limpa, pois o mesmo diploma legal atentaria contra o princípio da presunção de inocência. Entretanto não é o entendimento predominante nos tribunais. $\mathrm{O}$ que enseja uma investigação minuciosa acerca dos variados posicionamentos acerca do princípio da presunção de inocência, o que passaremos a ver a seguir.

\section{LEI DA FICHA LIMPA (LEI COMPLEMENTAR № 135 DE 2010)}

A priori, antes de adentrarmos ao estudo reflexivo acerca da Lei da ficha limpa, insta destacar que atualmente, o referido diploma legal tem se mostrado um instrumento plenamente eficaz, na busca incessante de retirar indivíduos cujo a reputação não precede os preceitos éticos para o exercício e gozo das atribuições políticas.

Como visto anteriormente, nossa Magna Carta prevê inúmeros casos de inelegibilidades no art. 14, §§ 4으 a 7으, assim como, no §9으, do referido artigo, conforme dispõe:

$\S$ 9o Lei complementar estabelecerá outros casos de inelegibilidade e os prazos de sua cessação, a fim de proteger a normalidade $e$ legitimidade das eleições contra a influência do poder econômico (BRASIL, 1988). 
Observa-se que o legislador prevendo a necessidade de complementação acerca das disposições sobre inelegibilidade, autorizou a edição de Lei Complementar para dispor sobre outros casos de inelegibilidades relativas, ou seja, que não estão relacionadas com determinada característica pessoal daquele que pretende candidatar-se.

Em consonância com o previsto no referido texto constitucional, foi sancionada, a Lei Complementar no 135 de 2010, que altera a Lei Complementar no 64/1990, trazendo novas hipóteses de inelegibilidade, almejando alcançar proteção máxima dos princípios norteadores da administração pública, no exercício do mandato, com o objetivo de melhorar o perfil dos candidatos aos cargos políticos. (BRASIL, 2010).

Deste modo verifica-se, que a Lei Complementar no 135 de 2010 é uma continuidade da Lei no 9.840/99, que trouxe um novo marco positivo na política brasileira almejando afastar de cargos políticos, indivíduos envolvidos em práticas de abusos políticos ou econômicos.

Vale salientar que a Lei da ficha limpa, introduziu ao ordenamento pátrio, novas causas de inelegibilidade, logo se faz necessário ponderar acerca do que vem a ser inelegibilidade.

Segundo José Afonso da Silva (2005) a Inelegibilidade revela-se um impedimento à capacidade eleitoral passiva (direito de ser votado). Obsta, pois, à elegibilidade. Não se confunde com a inalistabilidade, que é impedimento à capacidade eleitoral ativa (direito de ser eleitor), nem com incompatibilidade, impedimento ao exercício do mandato depois de eleito.

Reafirma tal posicionamento ao reflexionar acerca da conceituação aludida por Alexandre de Moraes (2014, p. 233):

A inelegibilidade consiste na ausência de capacidade eleitoral passiva, ou seja, da condição de ser candidato $\quad \mathrm{e}$ consequentemente, poder ser votado, constituindose, portanto, em condição obstativa ao exercício passivo da cidadania.

A inelegibilidade, como se verificou é algo que há muitos anos tem causado relevantes discussões no mundo jurídico, tendo em vista tratar-se de uma temática extremamente importante para um Estado Democrático de Direito.

O fruto de tal condição, e a necessidade de se afastar dos cargos políticos parlamentares cujo comportamento moral não é exemplar, não condizendo assim com o esperado dos representantes, agindo sem ética e decoro.

Entretanto a principal polêmica que gira em torno da constitucionalidade da Lei da Ficha Limpa é a causa de inelegibilidade em face de decisão judicial condenatória que não transitou em julgado.

A Constituição Federal dispõe: Art. 5o (in omissis) "LVII - ninguém será considerado culpado até o trânsito em julgado de sentença penal condenatória". (BRASIL, 1988).

O dispositivo supracitado consagra o princípio da presunção da inocência. Inúmeros juristas entendem que a Lei 135 de 2010 ataca esse princípio logo seria suficiente para considerá-la inconstitucional.

Nesse sentido leciona Silveira (2011, p.11):

A partir de uma análise jurídica, é difícil defender a constitucionalidade da Lei Complementar $n$. 135/10, quando a pretensão é impedir de obter o registro de candidatura a cidadãos que tiverem condenação criminal por órgão colegiado, ainda que caiba recurso, porque definidos como 'inelegíveis', porque afronta a presunção de inocência conforme aponta a Constituição Federal, onde só poderá ser considerado criminoso depois da sentença condenatória transitada em julgado.

Como visto, inúmeros juristas entendam pela inconstitucionalidade da Lei 135 de 2010, conhecida como Lei da Ficha Limpa, pois o mesmo diploma legal atentaria contra o princípio da presunção de inocência. Entretanto não é o entendimento predominante nos tribunais. $\mathrm{O}$ que enseja uma investigação minuciosa acerca dos variados posicionamentos acerca do princípio da presunção de inocência, o que passaremos a ver a seguir. 


\section{O PRINCIPIO DA PRESUNÇÃO DE INOCÊNCIA}

De início, deve-se observar que o art. 5, LVII, da Constituição Federal, dispõe que "ninguém será considerado culpado até 0 trânsito em julgado de sentença penal condenatória". (BRASIL, 1988).

Logo, se houver um recurso disponível ausência de trânsito em julgado deve(ria) imperar o princípio da presunção de inocência, não sendo admissível dar início a algo a pena que somente poderia ser imposta a um culpado.

Assim ensina-nos Brito, Fabretti e Lima (2015, p. 15-16):

O princípio do estado de inocência impede o cumprimento da pena imposta na sentença recorrível, o lançamento do nome do réu no rol dos culpados antes do trânsito em julgado da sentença penal condenatória, e configura a prisão antes do trânsito em julgado da sentença penal condenatória como algo excepcional.

Atualmente, prepondera a incerteza sobre o tema, o que também promove a descrença da população no Poder Judiciário e traz insegurança jurídica para quem atua na prática forense.

Ademais, ao lado da presunção de inocência constitucionalmente prevista, temos a previsão do art. 283 do Código de Processo Penal (1940):

Art. 283. Ninguém poderá ser preso senão em flagrante delito ou por ordem escrita e fundamentada da autoridade judiciária competente, em decorrência de sentença condenatória transitada em julgado ou, no curso da investigação ou do processo, em virtude de prisão temporária ou prisão preventiva.

Deste modo, verifica-se que aos olhos da melhor doutrina, o princípio da presunção de inocência, trata-se de um princípio absoluto, tendo em vista que a nossa própria Magna Carta, assim como legislação infraconstitucional prece

que ninguém será privado de sua liberdade sem que tenha se esgotado todas as vias recursais cabíveis não havendo o transito em julgado da sentença condenatória.

Sendo assim, observa-se a necessidade de se ponderar sobre a relativização do princípio da presunção de inocência, conforme análise do Habeas Corpus, julgado pelo Supremo Tribunal Federal.

\section{A RELATIVIZAÇÃO DO PRINCÍPIO DA PRESUNÇÃO DE INOCÊNCIA: HC 126.292 DO STF}

Devido à grande divergência na seara jurídica acerca da inconstitucionalidade ou não da lei da ficha limpa assim como da condenação pós-segunda instancia, nossa Suprema Corte viuse obrigada a pacificar as divergências anteriormente discutidas.

Neste sentido leciona Fernando Capez (2018), vejamos:

O novo entendimento do
Supremo Tribunal Federal,
que relativizou o princípio
do estado de inocência.
Em julgamento proferido
em Plenário, por maioria
de votos, o STF entendeu
que o art. 283 do Código
de Processo Penal não
impede o início da
execução da pena após
condenação em segunda
instância e indeferiu
liminares pleiteadas nas
Ações Declaratórias de
Constitucionalidade (ADCs) n. 43 e 44.

Observa-se que houve uma tentativa frustrada de entidades de classes congêneres como a Ordem dos Advogados do Brasil, em declarar inconstitucional a Lei 135 de 2010, sobre as alegações de que tal norma atenta contra princípios constitucionais.

Frente tal situação o Supremo Tribunal Federal, visualizou a necessidade posicionar-se acerca do tema. Logo Indeferiu as liminares arguidas nas Ações declaratórias de constitucionalidade no 43 e 44 e julgou favorável o HC 126292 de 2016, o que merece transcrição:

CONSTITUCIONAL.

HABEAS CORPUS.
PRINCÍPIO
CONSTITUCIONAL DA
PRESUNÇÃO
INOCÊNCIA (CF, ART. 5 50,


LVII). SENTENÇA PENAL CONDENATÓRIA

CONFIRMADA POR

TRIBUNAL DE SEGUNDO GRAU DE JURISDIÇÃO. EXECUÇÃO PROVISÓRIA. POSSIBILIDADE. 1. A execução provisória de acórdão penal condenatório proferido em grau de apelação, ainda que sujeito a recurso especial ou extraordinário, não compromete 0 princípio constitucional da presunção de inocência afirmado pelo artigo 50, inciso LVII da Constituição Federal. 2. Habeas corpus denegado. (STJ, Tribunal Pleno, HC 126292, Rel. Min. Teori Zavascki, julgado em 17/02/2016).

Vale apontar, trecho do voto do Ministro Relator Teori Zavascki (2016, p.16):

A execução provisória de acórdão penal condenatório proferido em grau de apelação, ainda que sujeito a recurso especial ou extraordinário, não compromete o princípio constitucional da presunção de inocência. Na linha da tese proposta, voto no sentido de denegar a ordem de habeas corpus, com a consequente revogação da liminar concedida. É O voto.

Anteriormente nossa Suprema Corte já vinha adotando este posicionamento, conforme verifica-se no julgamento do HC 68.726 (Rel. Min. Néri da Silveira), realizado em 28 de junho de 1991, onde entendeu que o princípio da presunção de inocência não impede a prisão decorrente de acórdão que, em apelação, confirmou a sentença penal condenatória recorrível, em acórdão assim ementado:

Habeas corpus. Sentença condenatória mantida em segundo grau. Mandado de prisão do paciente. Invocação do art. 50, inciso LVII, da Constituição.
Código de Processo Penal, art. 669. A ordem de prisão, em decorrência de decreto de custódia preventiva, de sentença de pronúncia ou de decisão e órgão julgador de segundo grau, é de natureza processual e concernente aos interesses de garantia da aplicação da lei penal ou de execução da pena imposta, após o devido processo legal. Não conflita com 0 art. 50, inciso LVII, da Constituição. De acordo com o § 20 do art. 27 da Lei no 8.038/1990, os recursos extraordinário $\mathrm{e}$ especial são recebidos no efeito devolutivo. Mantida, por unanimidade, a sentença condenatória, contra a qual o réu apelara em liberdade, exauridas estão as instâncias ordinárias criminais, não sendo, assim, ilegal o mandado de prisão que órgão julgador de segundo grau determina se expeça contra o réu. Habeas corpus indeferido.

Deste modo, verifica-se que o referido diploma legal, embora seja motivo de constantes discussões na seara jurídica, acerca de sua constitucionalidade constata-se que não há que se falar em inconstitucionalidade, uma vez que nossa Suprema Corte entende que a prisão decretada em segundo grau jurisdicional não fere o princípio da presunção de inocência.

Logo, essa regra se aplica também aos agentes políticos, que após terem reafirmado em segundo grau a sentença condenatória proferida pelo juízo a quo, pode ter o início de sua execução decretada, o que de pleno acarreta a condição de inelegibilidade política, implicando ao apenado todas as condições negativas que prevê a Lei 135 de 2010.

\section{CONCLUSÃO}

Ao findar breves considerações acerca do tema proposto, conclui-se que os direitos 
políticos são assegurados a todos os indivíduos de uma determinada sociedade, entretanto nem todos podem participar, uma vez que legislador originário criou condições de desigualdade nítida, uma vez que impõe uns, faculta a outros delimita idade mínima para cargos ou impõe condições especificas para a sua elegibilidade.

Observa-se que a elegibilidade é algo extremamente importante, tendo em vista que a ausência deste requisito objetivo impossibilita $o$ ingresso de determinado individuo a cargos políticos.

Vale ponderar ainda acerca inelegibilidade visto tratar-se especificamente de condições que impedem a candidatura, assim como, o ingresso ao cargo político. Nota-se que além dos requisitos objetivos previsto em nossa Magna Carta, existem outros requisitos em legislação infraconstitucional, como na Lei $135 / 2010$, a Lei da Ficha Limpa, cujo sua própria intitulação caracteriza-se como uma nova condição de elegibilidade.

Entretanto a Lei da ficha limpa tem sido constantemente alvo de crítica na seara jurista, toda via a quem entenda pela inconstitucionalidade da Lei 135 de 2010, pois o mesmo diploma legal atentaria contra o princípio da presunção de inocência. Ademais este não é o entendimento predominante nos tribunais. $\mathrm{O}$ que enseja uma investigação minuciosa acerca dos variados posicionamentos acerca do princípio da presunção de inocência.

Constata-se que a Lei Complementar 135 de 2010, embora seja alvo de constantes discussões na seara jurídica, acerca de sua (in) constitucionalidade, esta revela-se ora totalmente constitucional, uma vez que nossa Suprema Corte entende que a prisão decretada em segundo grau jurisdicional não fere o princípio da presunção de inocência.

Logo, essa regra se aplica também aos agentes políticos, que após terem reafirmado em segundo grau a sentença condenatória proferida pelo juízo a quo, pode ter o início de sua execução decretada, o que de pleno acarreta a condição de inelegibilidade política, implicando ao apenado todas as condições negativas que prevê a Lei Complementar 135 de 2010.

Ressalta-se que o presente trabalho é extremamente relevante, por tratar-se de um tema recente, onde inexiste uma concretude acerca das alterações trazidas com a Lei Complementar 135 de 2010, devendo assim servir de estimulo para operadores do direito, assim como estudantes de ciências jurídicas e áreas afins, pois o tema não se esgota com esta pesquisa havendo a possibilidade de se explorar as mais diversas vertentes, acerca da ilegalidade ou não da prisão após a condenação em segunda instância.

\section{REFERÊNCIAS}

BRASIL. Constituição (1988). Constituição da República Federativa do Brasil. Brasília: Senado Federal, 1988.

BRASIL. Lei complementar no 135 de 04 de junho de 2010. Altera a Lei Complementar no 64 , de 18 de maio de 1990, que estabelece, de acordo com o $\S 9^{\circ}$ do art. 14 da Constituição Federal, casos de inelegibilidade, prazos de cessação e determina outras providências, para incluir hipóteses de inelegibilidade que visam a proteger a probidade administrativa e a moralidade no exercício do mandato. Diário Oficial da União, Brasília, DF, 04 jun. 2010. Disponível em: https://www.planalto.gov.br/ccivil_03/leis/lcp/lc p135.htm. Acesso em: 10 jan. 2019.

BRASIL. Supremo Tribunal Federal. Acordão. n. ${ }^{\circ}$ 126.292 Habeas Corpus $n^{\circ}$. 126.292. Relator. Ministro Teori Zavascki. Brasília 17 de Fevereiro de 2016. Disponível em: http://redir.stf.jus.br/paginadorpub/pagin ador.jsp?docTP=TP\&docID=10964246.

Acesso em: 10 jan. 2019.

BRITO, A. C.; FABRETTI, H. B.; LIMA, M. A. F. Processo penal brasileiro, 3 ed. São Paulo: Atlas. 2015.

CAPEZ, F. Curso de processo penal. 25. ed. São Paulo: Saraiva. 2018.

MORAES, A. Direito constitucional. 15. ed. São Paulo: Atlas, 2014.

SILVA, J. A. Curso de direito constitucional positivo. 24 ed. São Paulo: Malheiros. 2005. 